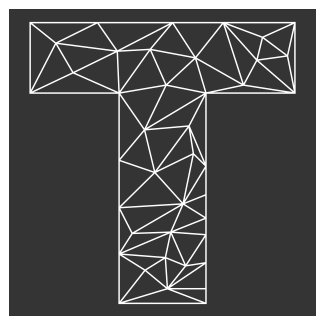

\title{
FORMAS DE INVERSIÓN MIGRANTE. REMESAS Y RETORNADOS INVERSORES EN SALVATIERRA, GUANAJUATO
}

Revista Trama

Volumen 7, número 2

Julio - Diciembre 2018

Páginas 87-106

ISNN-1659-343X

http://revistas.tec.ac.cr/trama
Forms Of Migrant Investment. Remittances And Returned Investors In Salvatierra, Guanajuato

Eduardo Fernández Guzmán ${ }^{1}$ Perla Shiomara del Carpio Ovando ${ }^{2}$

Fecha de recepción: 13 de abril de 2018 Fecha de aprobación: 13 de setiembre de 2018

Fernández, E. y del Carpio, P. (2018). Formas de inversión migrante. Remesas y retornados inversores en Salvatierra, Guanajuato, Trama, revista de ciencias sociales y humanidades, Volumen 7, (2), págs. 87-106.

DOI: https://doi.org/10.18845/tramarcsh.v7i2.3943
1. Profesor-Investigador. Departamento de Estudios Culturales, Demográficos y Políticos, Campus Celaya-Salvatierra de la Universidad de Guanajuato. Guanajuato, México. Correo electrónico: kutibirrin10@gmail.com

2. Profesora-Investigadora. Departamento de Estudios Sociales, Campus Celaya-Salvatierra de la Universidad de Guanajuato. Guanajuato, México. Correo electrónico: shiomarartesania@gmail.com 


\section{Resumen}

El asunto concerniente de las remesas e inversión migrante plantea importantes retos teóricos y metodológicos. La relevancia de estos depende en gran medida del espacio de análisis, si es de carácter global, regional o local, o si se localiza en zonas urbanas o rurales, o cuál enfoque epistemológico se elige para abordarlo. Aunque lleva décadas debatiéndose sobre los impactos positivos o negativos, la discusión sigue en la palestra y con solo revisar la copiosa literatura al respecto, nos enteramos de las diferencias tanto en el paradigma teórico como en las valoraciones del impacto en las localidades, las regiones y los países involucrados. Para la entidad guanajuatense, este no es un asunto menor. La migración internacional a Estados Unidos tiene una acendrada tradición en el estado, y por consecuencia, han sido múltiples los efectos para muchos pueblos y municipios, y sin duda alguna, las remesas sociales y económicas y la actividad empresarial han incidido de manera significativa en la región. La comprensión integral del fenómeno de la migración y en particular de la inversión migrante, merece de un análisis más ponderado y una comprensión más allá de triunfalismos descontextualizados y coyunturales. La relevancia y objetivo de este estudio de caso de corte comparativo, sustentado teórica y metodológicamente desde la historia del presente y la historia oral, es establecer que la inversión de las remesas y el retorno inversor va más allá de las consideraciones volitivas y subjetivas de los potenciales emprendedores. La vinculación de factores macro, meso y microestructurales son esenciales para entender proyectos de esta naturaleza. Se realizaron 64 entrevistas semiestructuradas. La entrevista intentó identificar los principales factores que influyen para que los migrantes, ya sea a través de las remesas a sus familiares o los retornados inviertan en su comunidad de destino. Las implicaciones del estudio son dobles: con fines de política pública en el apoyo a la inversión migrante, y de corte teórico, poner a prueba la teoría del proceso migratorio en un estudio de caso comparativo.

Palabras clave: negocios remeseros, migración de retorno, migración internacional.

\section{Abstract}

The issue of remittances and migrant investment poses important theoretical and methodological challenges. The relevance of these depends to a large extent on the space of analysis, whether it is global, regional or local, or whether it is located in urban or rural areas, or which epistemological approach is chosen to address it. Although it has been debated for decades about the positive or negative impacts, the discussion is still in the forefront and, just by reviewing the copious literature, we learn about the differences both in the theoretical paradigm and in the impact assessments in the localities, regions and the countries involved. For the entity from Guanajuato, this is not a minor issue. International migration to the United States has a strong tradition in the state, and as a result, the effects have been manifold for many towns and municipalities, and without a doubt, social and economic remittances and business activity have had a significant impact on the region. The comprehensive understanding of the phenomenon of migration and in particular of migrant investment deserves a more weighted analysis and an understanding beyond decontextualized and conjunctural triumphalism. The relevance and objective of this comparative case study, supported theoretically and methodologically from the history of the present and oral history, is to establish that the investment of remittances and the return on investment goes beyond the volitional and subjective considerations of the potential entrepreneurs. The linking of macro, meso and microstructural factors are essential to understand projects of this nature. 64 semi-structured interviews were conducted. The interview sought to identify the main factors that influence migrants, whether through remittances to their families or returnees to invest in their community of destination. The implications of the study are twofold: for the purposes of public policy in support of migrant investment, and of a theoretical nature, to test the theory of the migratory process in a comparative case study.

Keywords: cremittance businesses, return migration, international migration. 


\section{I.INTRODUCCIÓN}

Los ya anunciados cambios climáticos y sus devastadoras consecuencias, las recurrentes crisis económicas, las incertidumbres políticas, las dificultades para consolidar las democracias, la exacerbación de los chovinismos, las presiones demográficas y las persistentes asimetrías de poder internacional, siguen alimentando con furor los movimientos migratorios en el mundo, y de hecho los agudizan. Los analistas de la migración afirman que los inusitados y veloces cambios que ha sido objeto el mundo contemporáneo han registrado inéditas características en los procesos migratorios no vistas en el pasado (Facchini, Frattini, Mayda, 2015). El incremento mostrado de estos movimientos en las últimas cuatro décadas se ha manifestado, además del vertiginoso aumento de la literatura al respecto (Aubry, Burzynsky, Docquier, 2016; Hatton, 2014), en oleadas y su subsecuente fortalecimiento de las redes sociales, comunidades transnacionales y en la incorporación de nuevos países emisores y receptores (Durand, Massey, 2010), trayendo consigo una mayor complejidad en causas y consecuencias en las sociedades de origen y destino.

Luego entonces, el fenómeno de la migración internacional es una cuestión de gran interés académico y político internacional. Según estadísticas del Consejo Nacional de Población (2012) en 1965 se registraron 65 millones de migrantes internacionales, aumentando visiblemente a 105 millones para el año de 1985 y 214 millones (3.1\% de la población mundial) para el año 2010.

Para 2015 según la International Organization for Migration (IOM) radicaron en Estados Unidos poco más de 46 millones de migrantes internacionales, lo que significa el $14.49 \%$ del total de su población. La mayoría son de origen mexicanos con una cifra de 12 050031 millones, y le siguen en importancia China (2 103 551), India (1 969 286) y Filipinas (1 896 031). Si reparamos en las cifras de los países que le siguen en importancia como receptores de inmigrantes, Alemania (12 millones), Rusia (11 643 276), y Arabia Saudita (10 millones), se tiene que Estados Unidos sigue siendo el lugar más atrayente a nivel mundial para los migrantes. Es decir, Estados Unidos en 2015 albergó el 19.1\% de los migrantes internacionales, muy por encima de Alemania (4.9), Rusia (4.8\%) y Arabia Saudita (4.2\%) que son los que le siguen en la escala de importancia (CONAPO, 2016). Es por ese motivo que la migración de México a Estados Unidos se ha trasformado en el mayor circuito migratorio entre dos naciones en el orbe (IOM, 2015; Zuñiga y Leite, 2006; Ibarra, 2007).

Más de cien años de historia migratoria entre estas dos naciones donde el mercado del vecino país del norte ha demandado de la asequible fuerza de trabajo de millones de mexicanos que ha dotado a ese país de un muy productivo recurso humano dispuesto a emplearse en las trabajosas faenas del campo, la industria y los servicios aportando a su desarrollo como máxima potencia mundial. Una rica historia, mucha de ella inédita, de ir y venir, de múltiples consecuencias tanto para las comunidades de origen y destino, las relaciones bilaterales y las políticas públicas, las comunidades trasnacionales, los clubes y las redes sociales, los impactos culturales y psicológicos, los éxitos y los fracasos, la cultura migrante. En suma, la migración internacional tiene causas y consecuencias diversas, responde a impulsos históricos y sociales en un proceso dialéctico e integral, y que en su historia contemporánea presenta índices de desplazamiento inéditos. La relevancia y objetivo de este estudio de caso de corte comparativo, sustentado teórica y metodológicamente desde la historia del presente y la historia oral, es establecer que la inversión de las remesas y el retorno inversor va más allá de las consideraciones volitivas y subjetivas de los potenciales emprendedores, y que la vinculación de factores macro, meso y microestructurales son esenciales para entender proyectos de esta naturaleza. Las implicaciones del estudio tienen una doble vertiente: con fines de política pública en el diseño de programas de apoyo a la inversión migrante; y de corte teórico, la relevancia estriba en poner a prueba la teoría del proceso migratorio en un estudio de caso comparativo. Vale señalar que es un estudio preliminar ceñido historiográficamente a la historia del presente por lo que no busca generalizaciones, solo ver la singularidad de esta compleja realidad migrante. En futuras investigaciones se plantearán objetivos más ambiciosos donde se busque contrastarla con otras realidades y estudios de caso similares es este.

\section{METODOLOGÍA}

Para esta investigación nuestras fuentes de información fueron primarias y secundarias. En relación con las primeras fue fundamental el trabajo de campo. Este constituye, por lo general, el medio 
más directo para el acopio de información. Trabajamos la observación y la exploración del terreno que es básicamente el contacto directo con el objeto de estudio (observación participante), el cuestionario y la entrevista, que consistió en el acopio cuantitativo y cualitativo de testimonios orales. Lo que se pretendió con la utilización de estos instrumentos de recolección de datos, fue recuperar la riqueza de las experiencias de los informantes, posibilitando la descripción, de aspectos y situaciones, vicisitudes, lugares donde trabajaron y se desenvolvieron que no se hallan, por lo general, registrados. Además, nos ofreció la posibilidad de un mayor contacto con la realidad de los exmigrantes, migrantes, retornados, sus familiares y lugareños permitiéndonos mejores oportunidades en la reflexión sobre nuestro objeto de estudio.

Las fuentes secundarias utilizadas fueron libros, revistas y censos. Ellas en su conjunto nos proporcionaron elementos teórico-metodológicos, el panorama histórico y contextual de la migración internacional México-Estados Unidos y de la inversión migrante alrededor del mundo; además tuvimos acceso a datos y estadísticas nacionales, estatales y locales, que en su conjunto no son posibles obtenerlas del trabajo de campo.

Este artículo se centra en la experiencia de dos modalidades de inversión migrante: los negocios remeseros y el retorno e inversión, por lo que los datos fueron obtenidos principalmente de entrevistas a familiares de migrantes (para el caso de los negocios remeseros) y migrantes retornados inversores. Se realizaron 64 entrevistas (32 para cada caso) semiestructuradas entre los meses de febrero y septiembre de 2014. Se eligieron a ellos ya que consideramos que son claves en la información y además excedieron a darnos la información. La entrevista intentó identificar los principales factores que influyen para que los migrantes, ya sea a través de las remesas a sus familiares o los retornados inviertan en su comunidad de destino.

Se obtuvieron datos sobre las variables sociodemográficas y económicas tales como empleo, habilidades, estado civil, sexo, edad de partida, nivel educativo, historial migrante familiar. Se les pidió que informaran sobre lugares de residencia, trabajos desempeñados, ingreso, ahorros, remesas, situación legal, su vocación empresarial y su relación con las historias laborales de sus padres, la edad cuando se convirtieron en empresarios, el capital financiero con el que iniciaron, el tipo de negocios que montaron, las habilidades, hábitos y comportamientos que se pudieron y no aplicar a las condiciones concretas de la comunidad de destino, y sus visitas, contactos, inversiones en su comunidad de origen.

Nuestro trabajo por lo tanto es una historia del presente metodológicamente basado en las historias de vida de los migrantes inversores, una historia inmediata comparativa e inédita por la naturaleza de sus vicisitudes y experiencias vividas, donde se obtuvieron claves socioculturales muy valiosas para entender las dinámicas de estas formas de inversión en una población localizada en unos de las entidades de México con mayor tradición migratoria internacional. Dada la naturaleza cualitativa basadas en las experiencias e historias de vida no se busca la representatividad, el objetivo es de carácter histórico y socio-antropológico.

\section{REMESAS Y MIGRACIÓN DE RETORNO}

Analizar las consecuencias del proceso migratorio permite comprender de una manera más profunda las singularidades de este fenómeno. Empero, hay investigadores que afirman (Herrera, 2006) que existe una carencia importante en cuanto al estudio de las consecuencias de la migración. Uno de los efectos de la migración se da en el plano económico individual y macroeconómico. El concepto de "capital humano" en la inversión del ciclo vital, ha sido estudiado como una de las consecuencias de este fenómeno. Desde una visión neoclásica se subraya que el individuo puede planear un superior rendimiento para sus futuros años de trabajo como migrante, lo que es calificado como una inversión de "capital humano" que incide en costos y origina beneficios. De las consecuencias macroeconómicas se sigue debatiendo ampliamente en cuanto a sus efectos (positivos o negativos) que ha obedecido esencialmente al marco teórico utilizado por el autor. Los inscritos en el paradigma marxista ponderan más los negativos ya que consideran avivan la inflación, hay un quebranto de capital humano y se agudiza la dependencia de las remesas; por otro lado, los afines a los modelos neoclásicos y funcionalistas destacan el lado positivo ya que creen que el flujo de remesas se expresa en una mayor estabilidad del tipo de cambio, de la balanza de pagos y otras aristas cardinales de la economía, como a nivel macroeconómico que se ve positivamente mostrado en los ingresos y el consumo familiar, en los niveles educativos, etcétera. 
Pero no solo se observa el impacto positivo de las remesas, sino también en la migración de retorno inversor (remesas socio-empresariales) y con ello el impacto al desarrollo y a la generación de empleos en algunas localidades de muy alta o alta intensidad migratoria, como la localidad objeto de nuestro estudio.

La migración internacional es un acontecimiento muy importante en las vidas de los individuos, las familias y las comunidades. Influye en la trayectoria de la vida de los migrantes e individuos que los rodean, conlleva a una reestructuración del hogar y genera reajustes demográficos y cambia la organización productiva de una comunidad, influyendo, de manera positiva o negativa, en el desarrollo económico y la estructura social. Por ello las consecuencias de la migración para las comunidades de origen son múltiples y presentan diferentes matices dependiendo a que se haga alusión (política, cultural, del comportamiento, socioeconómica), del nivel de análisis (el individuo, el hogar, la comunidad, la región, el estado, el país) y del contexto específico de la migración (el momento histórico en que ocurre, la tradición migratoria y el perfil del migrante).

Todas estas características varían de región a otra y tienen un impacto desigual en la vida de las familias y las comunidades. El impacto de las remesas económicas y sociales en las comunidades no prescinde de estas consideraciones. De hecho, gran parte del debate y la concepción sobre las consecuencias positivas o negativas de la migración en los países y comunidades se ha centrado en la polémica sobre el uso de las remesas. Así tenemos que la mayor parte de la literatura sobre el impacto de las remesas se ha centrado en aspectos económicos: su uso productivo o no productivo, su potencial para reactivar el crecimiento económico; su impacto en los niveles de pobreza y la desigualdad. La asignatura pendiente es sobre el impacto de las remesas en la estimulación al cambio dentro de una variedad de instituciones socioculturales como las jerarquías locales de estatus, las relaciones de género, la reorganización del hogar, los patrones y las normas de consumo en la comunidad, las percepciones ante la migración y su influencia en las expectativas sobre las trayectorias vitales de las generaciones más jóvenes (Vertovec, 2006).

La migración mexicana a Estados Unidos, para Lozano y Olivera (2007), ha representado, en el transcurso de su historia, un flujo importante de recursos monetarios, que han posibilitado el sostén de millones de hogares mexicanos, en especial en aquellos estados de mayor volumen de migrantes.
Pero, acentúan los autores, el impacto económico de las remesas en México es marcadamente desigual y heterogéneo.

En las últimas décadas las relaciones económicas de los migrantes con su lugar de origen han sido objeto de una extensa investigación multidisciplinar sobre la relación entre migración y desarrollo (Clemens, Ozden y Rapoport, 2014). Implícitamente, las remesas expresan lazos sociales a larga distancia de solidaridad, correspondencia y deber moral, que articulan a los migrantes con sus parientes y amigos a través de las fronteras nacionales controladas por los Estados.

Aun cuando las remesas monetarias han sido objeto de discusión y análisis académico y político, ponderando los beneficios de la migración, los pros y contras de las remesas sociales y técnicas concretizadas en la migración de retorno (inversores, jubilados, desarraigados, traficantes, enfermos, etc.) están llamando cada vez más la atención de los científicos sociales.

La complejidad de las remesas de la misma forma está en el terreno estrictamente económico y de ahí que haya investigaciones que se decanten por entender los ejemplos y tipos diferentes de remesas (Goldring, 2004; Durand, 1994). Otras han indagado la problematización de las remesas en la dimensión de las motivaciones más profundas de los migrantes por enviar estos recursos a sus comunidades de origen. Para Poirine (2006) hay dos modelos de motivación de las remesas: el altruismo y el autointerés.

La investigación sobre la migración internacional, las remesas y sus consecuencias en los lugares de origen abarcan una literatura considerable. Es pues, importante conocer los resultados de estas investigaciones, que tratan escenarios socioeconómicos, culturales, políticos e históricos muy específicos, pues sus conclusiones facilitan la comprensión de los componentes que incitan o desalientan el uso productivo de las remesas.

Un gradual debate científico ha surgido en relación con la importancia de las remesas para el desarrollo. Muchos manifiestan que, debido a la gran cantidad de dinero enviado por los migrantes, las remesas favorecen positivamente al desarrollo (Díaz, Soydemir, 2013). Otros menguan los hipotéticos efectos positivos, minimizando la contribución al desarrollo de estos recursos monetarios (León-Ledesma y Piracha, 2004). 
Es decir, del lado positivo, la premisa nodal es que las remesas mejoran las condiciones de vida de los hogares que las reciben; que hay un estímulo a la inversión productiva en la creación de empresas; inversiones en capital humano, educación, salud, espíritu empresarial y la reducción de la pobreza (Adams, Cuecuecha, 2013; Ravinesh, 2013). Además, es tangible una gama de efectos multiplicadores que dinamizan el mercado interno regional. También favorece la economía de los países en desarrollo, ya que contribuye a la balanza de pagos, y provee de intercambio extranjero y fondos significativos para el desarrollo económico (Karafolas, 1998). Y a nivel micro tiene también sustanciales efectos en el hogar, la oferta de trabajo y el consumo (Guha, 2013).

Y por su parte, el enfoque negativo señala que las remesas constituyen un gasto no productivo; que facilita a la dependencia económica y un uso exclusivo para la sobrevivencia de la familia; además, de que hay pocos alicientes para el desarrollo regional y nacional, lo que se viene a manifestar en la inflación de bienes y servicios, mano de obra y la desigualdad social y salarial. Otro aspecto que poco se ha examinado es en relación con el efecto de las remesas para el desarrollo de los países de destino. Alkhathlan (2013) para el caso de Arabia Saudita, afirma, que la transferencia de billones de dólares repercute negativamente en el crecimiento del país, ya que esos caudales salen y no se consumen internamente.

Otros estudiosos además relacionan remesas con inversiones específicas en negocios o actividades agrícolas. Algunas investigaciones (Davis, Lopez-Carr, 2014; Fransen, Mazzucato, 2014; Conway, Cohen, 1998) encuentran que el gasto de las remesas, la circulación $y$ el retorno migrante tienen contribuciones positivas a los hogares de las comunidades. La inversión de las remesas tiene más efectos positivos que negativos cuando las relaciones entre la gente e interacciones son examinadas a una microescala. Así, nos dicen estos autores, en México, América Latina y el Caribe las remesas tienen influencias positivas en la vida de la gente rural ya que, en las situaciones de crisis social y amplias privaciones, el gasto de las remesas en necesidades básicas no puede ser admitido como negativo.

Hay autores (Adams, Cuecuecha, 2013; Goldring, 2004) que dicen que se debe poner especial atención en lo que ha denominado el argumento social del desarrollo, es decir, que las remesas son un factor de inversión en capital humano debido al mejoramiento en la nutrición, la educación y la salud, y que esta inversión es un elemento clave en el proceso de desarrollo. Acorde con este razonamiento Koc y Onan (2004) sostienen que las remesas tienen un impacto positivo para el bienestar del hogar, y los hogares que reciben estos recursos son más ricos que los que no lo reciben. Estos autores critican a quienes utilizan el término inversión no productiva cuando se refieren al consumo directo, la vivienda y a la compra de terrenos. Son definiciones arbitrarias de "inversión productiva". Koc y Onan, concluyen, que el acceso a una mejor nutrición, y asignación a más recursos a la educación, son sin duda, formas de inversión productiva. Igualmente, interesante es lo que dice Zarate-Hoyos (2004) cuando establece que las remesas tienen diversos usos, por ejemplo, los gastos en una nueva casa, o la mejora de la que habitan, tienen un impacto positivo en la higiene y en el bienestar físico elevando la productividad laboral y aumentando el valor de la propiedad. Salas (2014) en Perú analiza el efecto de la migración internacional y las remesas en los niños que se quedan. Y afirma que las remesas tienen un efecto positivo sobre la posibilidad de enviar a los hijos a escuelas privadas.

Otra vertiente interesante es la que toca Anzoategui, Demirguc y Martínez (2014) quienes analizan el impacto de las remesas en la inclusión financiera. Los hogares que reciben remesas tienen más posibilidades de tener una cuenta de depósito en una institución financiera, y en requerir y recibir un préstamo. Para Karunarathne y Gibson en un estudio en Sri Lanka y Samoa (2014) afirman que mucha gente está deficientemente preparada para hacer grandes decisiones financieras. Un importante subgrupo como son los migrantes se han especializado en necesidades financieras relacionadas con las remesas. Kosse y Vermeulen (2014) aseguran que, con respecto a los mercados financieros, recientes estudios muestran que las remesas pueden promover el desarrollo financiero doméstico.

Algunos estudios argumentan que la existencia de bienes familiares puede servir como un estímulo para remitir dinero porque los migrantes desean reclamar estos bienes en la comunidad de origen cuando ellos retornen. La literatura sugiere que la relación entre remesas y la inversión en negocios es compleja. Las remesas pueden inducir a la inversión de negocios, pero también la existencia de ellas, por sí misma, puede atraer las remesas y la migración de retorno con potenciales posibilidades de inversión.

Es interesante los argumentos empleados por Lozano (2007) quien considera que es necesario no ser maniqueo cuando se trata de analizar los impactos de 
las remesas ya que traen consigo tanto efectos positivos como negativos. Todo depende de los contextos y condiciones en los que están inmersos. El impacto es desigual según la geografía que se analice. Y de este modo el significado de las remesas adquiere matices específicos.

Eso es en cuanto a la problematización de las remesas económicas, sociales, tecnológicas, etc. Es momento de hacer un alto en relación con los migrantes de retorno inversores. La investigación del retorno no tiene mucho de ser analizada. Pese a su juventud, han salido a la luz sesudas reflexiones de una elaboración teórico y empírica muy destacada. Semejante a los interesados en el tema de las migraciones de salida, los de retorno lo han hecho desde el análisis de histórico, antropológico, sociológico, demográfico, económico, político, metodológicamente desde el ángulo cualitativo o cuantitativo, o con una mayor inclinación por lo teórico o lo empírico. Es digno de mencionar que en todos los continentes hay estudiosos de esta arista de la migración, y como en la literatura que a continuación se describe, se observa que en las últimas décadas ha avivado un interés muy grande sobre la migración de retorno ${ }^{3}$. Que, dicho sea de paso, como afirman Newbol y Bell (2001), se ha convertido en un nicho especializado dentro de la literatura de la migración.

Investigadores pioneros del estudio sobre el fenómeno del retorno se lo debemos a académicos europeos (Sjaastad, 1962; R.T. Appleyard ,1962; Goldstein 1964). Los estudios precursores del retorno en la década de 1960, además de no ser profusos, se circunscribieron al continente europeo. En ellos se observa una inquietud teórica por interpretarlos, como abordarlos metodológicamente (fuente de datos, su unidad de análisis y sus técnicas analíticas) y el bastimento de tipologías por medio de la mixtura de los métodos cualitativos y cuantitativos. Es el inicio de una copiosa y muy prolífica subdisciplina de investigación en el tema de la migración.

En los decenios de 1970 y de 1980 el interés sobre migración de retorno es aún modesto, sin embargo, destaca el elaborado por Cerase (1974), debido a la impronta de las contribuciones teóricometodológicas de sus antecesores. Vale mencionar que el campo de investigación va ampliándose a otras áreas geográficas, principalmente a Norteamérica, Estados Unidos y Canadá (Vanderkamp, 1971; Lee, 1974; Da Vanzo y Morrison, 1981), Europa (Kirwan y Harrigan, 1986; Papademetriou; 1985; McLean y Kousis; 1988), Israel (Toren, 1976) avivando interés incluso a nivel de la Organización de Naciones Unidas (Glasery Habers, 1974). Aunque imperan los estudios de naturaleza global, y del retorno en general, ya brotan las investigaciones con asuntos más precisos y concretos, como por ejemplo el retorno de profesionistas. Estas investigaciones encuentran claves de este tipo de movimientos: sus pautas espaciales, las peculiaridades de los migrantes y las causas del retorno, recalcando el valor de la historia de vida y experiencia migrante, su naturaleza selectiva y sus disímiles consecuencias.

Transcurridos las primeras 3 décadas de investigación sobre el retorno migrante los estudios fueron primordialmente de europeos y estadounidenses, delimitados en estas zonas continentales. No es sino hasta la década de 1990 que investigadores de otro origen geográfico como el Caribe, África, Asia, Islas del Pacífico exploran este fenómeno que se presentaba con fuerza en sus países y regiones. El volumen, como la variedad espacial y temática resalta en este periodo. Hay expectación por describir las raíces históricas (Chandra, 1997), las cuestiones étnicas (Vasileva, 1992), contrastes de género (Gmelch y Gmelch, 1995), la inversión de ahorros y la conducta económica del retornado (Galor y Stark, 1990), las repercusiones culturales y ámbito familiar tanto a nivel global (Diatta y Mbow, 1999) como en estudios de caso (Muschkin, 1993).

En el siglo XXI el aumento de la literatura de la migración de retorno ha sido visible, así como la investigación de este fenómeno alrededor del mundo. Además de los asuntos habituales basados en las secuelas económicas, las circulaciones internas, el retorno de jubilados, el retorno por motivaciones étnicos, otros temas aparecen en escena: problemas mentales de los retornados, los niños retornados y sus consecuencias en la salud mental y el desempeño académico, los contagiados de SIDA, los dificultades de integración (Vuorenkosky, et-al,2000; Pinoy Verde, 2006; Verde, 2006; Arowolo, 2000; Knodel y Vanlandingham, 2003), la atracción de migrantes talentosos (Dai, Liu y Xie, 2014; Jonkers y Cruz-Castro, 2013; Dustmann, Fadlon y Weiss, 2011), los estudios de caso basados en la historia oral, los estudios multidisciplinares que analizan los efectos económicos y socio-culturales, y el retorno y su relación con elementos transnacionales (Gowans, 2006; Ni Laoire, 2007; Tannenbaum, 2007; Potter, Conway y St. Bernard, 2009). Teórica y metodológicamente predomina la visión neoclásica del capital humano (Constant y Massey, 2002; Hunt, 2004; Williams y Baláz, 2005) y se abren paso los estudios de las redes sociales y los vínculos transnacionales, y la perspectiva neoinstitucional. En relación al análisis

3. Y sobre su conceptualización. Al respecto Gmelch exhorta a diferenciar la migración de retorno, la remigración y la migración circular. El retorno es definido como el movimiento de los migrantes de vuelta para reinsertarse en su tierra natal; la remigración se refiere a la gente quien regresa a su patria y luego migra de nueva cuenta; y la circular es el frecuente movimiento entre dos o más lugares tales como una migración laboral temporal o estacional (Gmelch, 1980:138). 
del retorno empresarial y los estudios comparativos se estudian de una manera más atenta en diferentes geografías del mundo debido a la importancia y a los efectos que ello implica en las comunidades de origen (Vera, Revilla y Schatzl, 2013; Marchetta, 2012; Black y Castoldo, 2009; Klinthall, 2006; McCormick y Wahba, 2001).

Cohen (2013) afirma que a migración de retorno se ha denominado por su gran relevancia como "el más grande capítulo no escrito en la historia de la migración". Consecuentemente en las últimas décadas la migración de retorno se ha convertido en un asunto de gran importancia en la agenda de las instituciones y políticas públicas. El creciente interés por el retorno como herramienta política ha sido atribuido a varios factores, incluyen el aumento del volumen de retornados y la política de repatriación de los países de destino, incluyendo movimientos voluntarios a países de origen o terceros países.

\section{SALVATIERRA, GUANAJUATO}

México, como bien es sabido, es uno de los destinos más importantes en el mundo de los envíos de remesas y del retorno de migrantes internacionales, ya sea de manera cíclica o definitiva. Los efectos de las remesas y el retorno inversor no se limitan a los hogares mexicanos receptores, sino que se extienden a la comunidad entera. Así tenemos, por ejemplo, que los envíos monetarios en las entidades tradicionales de expulsión migrante en México (Michoacán, Jalisco, Guanajuato, Zacatecas) son sobresalientes.

Durante el periodo de 1990-2005, ingresaron a México 113 mil 802.82 millones de dólares por concepto de remesas. En términos de participación por estado en el año 2005 Michoacán recibió el 12.95\% del total de las remesas, Guanajuato el $8.56 \%$, Jalisco el $8.45 \%$, Estado de México el $8.36 \%$ y el DF el $7.25 \%$. Otro de los indicadores importantes para medir la relevancia de la migración para el país es el número de municipios con alguna intensidad migrante a Estados Unidos. Durante el año 2000 tan sólo 92 municipios del país reportaron una nula participación migratoria (localidades principalmente del sur y suroeste del país); 2350 municipios registraron algún contacto con el vecino país del norte. De estos, 492 son de alta y muy alta intensidad migratoria; 392 fueron de una intensidad media, y 1466 municipios exhiben una muy baja intensidad migratoria. También es de resaltar que más de la mitad de los municipios de Aguascalientes (72.7\%), Zacatecas (71.9\%), Jalisco (65.3\%), Michoacán (62.8\%), Durango (59.6\%) y Guanajuato (58.7\%) cuentan con una intensidad alta o muy alta de migración (Reyes, 2006).

El estado de Guanajuato para el 2010 contó con una población de 5.4 millones, de los cuales León alberga a 1.4 millones, Irapuato a 529 mil, Celaya 468 mil, siendo las ciudades con mayor número de habitantes. Además de históricamente ser una entidad expulsora de migrantes internacionales, Guanajuato tiene un importante flujo de inmigrantes de otros estados de la República Mexicana, así, el 10\% de los radicados en este estado vieron su primera luz en otra entidad, principalmente del D.F -131 mil-, Michoacán -68 mil-y Jalisco -56 mil- (INEGI, 2010).

Tomando los datos del INEGI (2010) la migración de mexicanos a Estados Unidos entre 2005-2010 fue de poco más de 1.1 millones, siendo el estado de Guanajuato el que aportó más con 119 mil, seguido de Jalisco con 86 mil y Michoacán con 85 mil. En ese mismo periodo hubo un $31.5 \%$ de migrantes de retorno a nivel nacional, Guanajuato observó un 27.8 $\%$ de su flujo. 


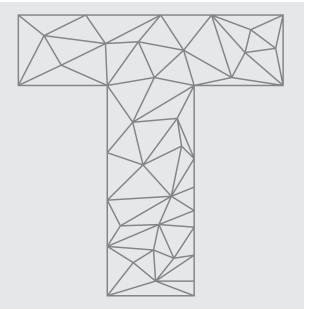

Las remesas en los últimos años, nos da cuenta CONAPO (2012), han sido de los ingresos por divisas más importantes para el país. En 1990 representaban la cuarta entrada más importante después de la exportación petrolera, del turismo y del saldo de la balanza comercial de maquiladoras. En 2010 se colocó en segundo lugar, sólo superado por la exportación de petróleo que arrojó cifras de $41 \mathrm{mmd}$. Vale mencionar para ir dimensionando la importancia de las remesas, que en México en el 2010 existían 29 millones de hogares de los cuales el $4.7 \%$ recibían remesas. Guanajuato en este contexto ha sido de los principales receptores en las últimas décadas. En 1995 captó 376 millones de dólares por debajo de Michoacán con 597 millones y Jalisco con 467 millones. El salto fue espectacular en 15 años, para el año 2010 Guanajuato se colocó en segundo lugar con 1978 millones de dólares (9.3\% del total nacional), sólo superado por Michoacán que recibió 2141 millones (10.1\%). Posición que sigue manteniendo, ya que, en el primer trimestre de 2012, según información emitida por BANXICO, entraron a la entidad guanajuatense 498.7 millones de dólares, 40 millones menos que Michoacán en dicho periodo.

Mapa de Salvatierra, Guanajuato, México

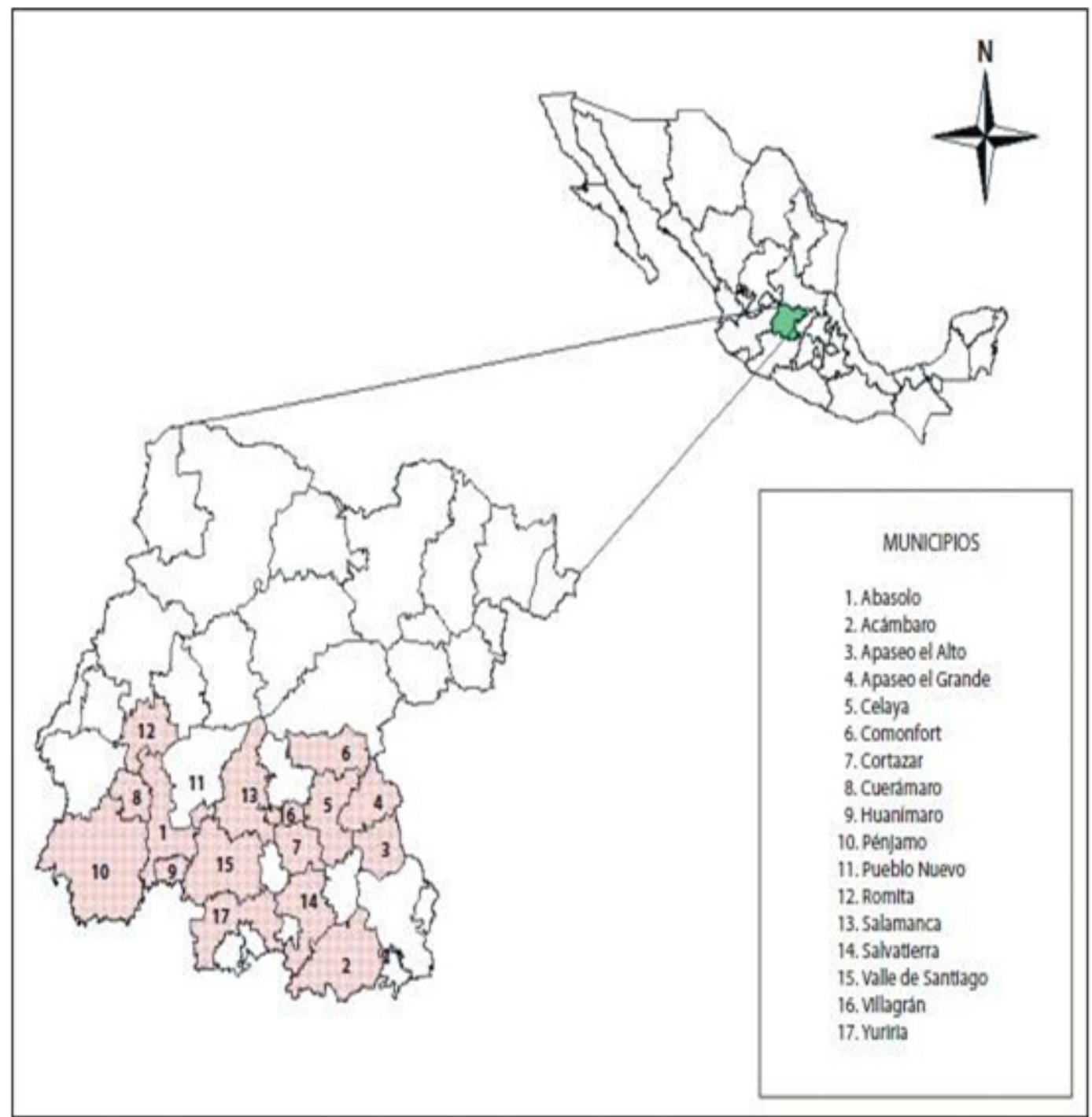

Fuente: CENAPRED, 2004. 
Otro parámetro para medir la importancia de la migración internacional en las entidades son los índices de intensidad migratoria. En México, tomando como base los datos del CONAPO, para el año 2010 cuatro estados presentaron la categoría de muy alta intensidad migratoria (Zacatecas, Guanajuato, Michoacán, Nayarit); 10 con alta intensidad; 8 con intensidad media; 2 con baja; y 8 con intensidad muy baja. Esto significa que de los 2456 municipios en el país existen 178 con muy alta intensidad migratoria y con alta hay 431 municipios, esto hace que casi el 25\% de los municipios en nuestro país tenga un movimiento migratorio de importancia considerable. Michoacán, por ejemplo, de 113 municipios, en 23 existe una muy alta intensidad migratoria y 46 con alta, es decir, más del $50 \%$ de los municipios michoacanos presenta un desplazamiento internacional muy significativo.

Algo muy semejante ocurre en Guanajuato, que ocupa el segundo lugar nacional en intensidad migratoria, tan sólo superado por Zacatecas. Para 2010 de los 46 municipios guanajuatenses, 15 arrojan una muy alta intensidad y 20 alta intensidad, esto significa que el $76 \%$ de los municipios en el estado tienen una dinámica migratoria a Estados Unidos muy sobresaliente.

Salvatierra con un rango de alta intensidad migratoria ocupa el lugar 31 en el estado y el 503 a nivel nacional. Este municipio cuenta con un total de 23896 viviendas de las cuales el $15.74 \%$ reciben remesas (el doble de la media estatal), el $4.50 \%$ cuenta con migrantes en Estados Unidos, 1.33\% cuenta con migrantes circulares y el $6.36 \%$ con migrantes de retorno.

Según las estadísticas del INEGI (2010) el porcentaje de la población migrante de retorno entre 2005 y 2010 fue del 31.5\% en el país, Nayarit presentó los porcentajes más altos con $53.3 \%$ y el más bajo fue Oaxaca con 15.8. Guanajuato registró en ese periodo $27.8 \%(85.4 \%$ de ellos a la misma vivienda y el $5.7 \%$ en otro lugar), casi igual al de Michoacán que alcanzó el $29.7 \%$.

Según datos del INEGI en el 2010 la población total de Guanajuato fue de 5486372 habitantes, de los cuales 494894 nacieron en otro estado. Salvatierra contó para ese año con una población de 97054 . Y si tomamos las cifras emitidas por el Consejo Nacional de Evaluación de la Política de Desarrollo Social sobre la Medición Municipal de la Pobreza 2010 Salvatierra muestra altos porcentajes de pobreza. El $59.7 \%$ de su población está en situación de pobreza, $49.7 \%$ está en situación de pobreza moderada, el $10.1 \%$ en pobreza extrema y tan solo $6.3 \%$ de la población no es pobre y no es vulnerable. El $90 \%$ cuenta con al menos una carencia social y el $26.4 \%$ con al menos tres carencias.

\section{NEGOCIOS REMESEROS $Y$ RETORNO INVERSOR MIGRANTE EN SALVATIERRA: RESULTADOS}

\section{Negocios remeseros}

En interesante en el plano comparativo lo que arroja el trabajo de campo en relación con estos dos planos de la inversión migrante. En relación con los negocios remeseros se realizaron entrevistas en diez localidades del municipio de Salvatierra (Salvatierra, San José del Carmen, San Isidro, El Capulín, Maravatío del Encinal, El Sabino, Rancho Nuevo, Urireo, San Miguel Emenguaro y San Nicolás de los Agustinos).

La edad promedio de los encargados de los negocios remeseros es de 44.59 años (19 mujeres y 15 hombres), 25 son casados, 2 solteros, 2 viudos y 3 divorciados. En cuanto a su nivel de escolaridad se observan que los niveles no son muy altos, el $11.76 \%$ no tienen estudios; el $29.41 \%$ cuentan tan solo con primaria incompleta o concluida; el $41.17 \%$ con algún año o secundaria finalizada; y el $17.64 \%$ con estudios de preparatoria.

Es interesante observar que el $96.87 \%$ de los propietarios de los negocios remeseros cuenta actualmente con algún familiar radicado en Estados Unidos. Algunos tan solo cuentan con un miembro en aquel país, y otros que pasan de los 20 familiares viviendo en dicha nación. Asimismo, tenemos que el $55.84 \%$ de los propietarios han ido alguna vez a Estados Unidos (un poco más del $50 \%$ lo hizo de manera indocumentada) y el resto jamás lo ha hecho.

Cuando se les preguntó por qué tanto él como su familiar se fueron a Estados Unidos las respuestas fueron básicamente de orden económico (mejorar económicamente, por necesidad económica, por falta de trabajo o salarios muy bajos aquí en México, por deudas y mejores condiciones laborales en Estados Unidos), y familiares (ver al esposo y a los hijos, ayudar a su familia, ver a familiares enfermos). 
La mayoría de los propietarios de negocios remeseros tienen una percepción favorable sobre la migración a Estados Unidos los argumentos se centran en afirmar que el municipio se beneficia económicamente debido a las remesas, hay más para comer, pagar deudas, ayudar a la familia, construir y remodelar las viviendas, se aprenden cosas nuevas y hay más movimiento comercial e inversiones. Al mismo tiempo hay comentarios que resaltan los perjuicios de esta en las localidades como lo son la separación de las familias, se quedan muchos hijos solos, la ida de muchos jóvenes, la falta de valores y respeto, los vicios aprendidos, el abandono de las tierras y el campo.

Generalmente se les pregunta a los migrantes sobre sus motivos y causas de migrar, pero hay un olvido de interrogar a los que se quedan, por sus causas de no irse a trabajar y radicar en Estados Unidos. Cuando se les aborda en relación con este aspecto sus respuestas giran en torno a lo difícil de ir por falta de documentos legales y el peligro de una frontera cada vez más vigilada y protegida, otros están muy a gusto con sus hijos y familiares aquí, y otros simple y llanamente responden que no quieren ni les llama la atención desplazarse.

Una de las consecuencias positivas del transnacionalismo migrante es el crecimiento del autoempleo, la formación de nuevos negocios y la creación de nuevos empleos en las comunidades de origen. Los negocios remeseros es una manifestación, en muchas de las veces modesta, de la movilidad social ascendente. O cuando menos es el tránsito de trabajador a propietario de una micro o pequeña empresa. De todos los propietarios entrevistados la gran mayoría de ellos anterior a su actividad empresarial eran trabajadores asalariados (hojalatería y pintura, limpieza, albañilería, mecánico, obrero en fábrica, jornalero en el campo, vendedor de casas, en tiendas entre otras) algunas amas de casa, y otros trabajaban sus tierras o ayudaban a cultivar a sus familiares.

Más de la mitad de los negocios que han creado son tiendas de abarrotes y tiendas de ropa. Lo demás son panaderías, renta de parcelas de cultivo, negocios de comida, puesto de verduras, vinaterías, locales de productos belleza y estéticas, construcción de locales para renta, papelerías, fruterías, entre otros. Es importante señalar que en la creación del negocio las remesas económicas de los familiares en Estados Unidos fueron fundamentales. Y en la mayoría de ellos, el apoyo fue de más de uno miembro familiar, que a través de un sistemático envío monetario fueron ahorrando para invertirlo en una actividad productiva. Unos declararon que invirtieron para su creación desde una suma considerable de 170 mil dólares hasta algo más modesto de 15 o 3 mil pesos. Los lazos de solidaridad y el compromiso familiar y comunitario fueron enlaces clave para consolidar una actividad productiva del transnacionalismo migrante en las últimas décadas en las poblaciones con alta tradición e incidencia migratoria a Estados Unidos.

Cuando menos en los últimos 20 años esta alternativa laboral ha permeado la dinámica de inversión en Salvatierra. De los 32 negocios remeseros analizados, dos tienen más de 20 años operando; cinco de 10 a 20 años; siete están en el rango de 5 a 10 años; catorce de 1 a 4 años; y cuatro de ellos son de reciente creación que no pasan el año de haberse inaugurado. Y en relación con la generación de empleos tenemos que el $46.87 \%$ son negocios operados solo por el propietario; el $21.87 \%$ por el propietario y un empleado; el $21.87 \%$ por el dueño y dos empleados; el $3.12 \%$ por el dueño y tres trabajadores; y el otro $3.12 \%$ el empleador tiene a su cargo a cuatro trabajadores.

A pregunta expresa de cuanto es su ganancia mensual el 50\% de los entrevistados no respondió aduciendo razones de seguridad y desconfianza por el clima de inestabilidad y crimen organizado que ha ejercido una presión sistemática de soborno en amplias franjas de la geografía del occidente de México. De los que respondieron el $37.5 \%$ declaró que las ganancias al mes oscilan entre mil y cinco mil pesos; el $9.37 \%$ de seis mil a diez mil; $y$ tan solo el $3.12 \%$ arriba de once mil pesos mensuales.

Es interesante observar las múltiples razones del porqué pusieron un negocio. Los motivos no solo responden al orden económico, sino que transitan por consideraciones familiares y de prestigio y estatus social. Así tenemos que la necesidad de ser patrón, traer más dinero, salir por su cuenta, aprovechar las buenas tierras, se vincula a razones de orden familiar, apoyar a los papás, para que el esposo regrese de Estados Unidos más pronto, muerte del esposo, o que los hijos no querían que trabajara tanto.

Un rubro también muy importante para determinar abrir un negocio es la tradición empresarial en la familia. El $65.62 \%$ de los entrevistados declaró tener antecedentes familiares en la actividad empresarial ya sea de los abuelos, tíos, padres o hermanos. Los negocios primigenios fueron carnicerías, tierras de cultivo, tiendas de abarrotes, 
venta de semillas y granos, la venta de comida, entre otras actividades. Mientras que el restante $34.37 \%$ no cuentas con antecedentes en el autoempleo y la creación de negocios.

Otro asunto que indagamos entre los propietarios de negocios remeseros es sobre si les gustaría o piensan irse a Estados Unidos a trabajar y vivir. El 57.70\% expresaron su negativa argumentando principalmente la carencia de documentos legales para pasar y establecerse en aquel país; la dificultad de irse por cuestión de la edad y enfermedades; los hijos vienen seguido; se sienten tranquilos en su pueblo y por razones familiares como no querer dejar solos a sus padres. Y el restante $42.30 \%$ manifestó su aprobación debido principalmente por estar con los familiares, y la otra razón de peso es para ahorrar, regresar e inyectarle más recursos a sus negocios para ampliarlos y así obtener más dividendos.

Cuando fueron abordados sobre si hubo o no apoyo del gobierno para establecer e impulsar su negocio llama la atención que la abrumadora mayoría (96.87\%) respondió que no recibieron apoyo alguno. Aseguraron que hay muchos trámites, y otros de plano desconocen que exista un programa oficial para este rubro. Existe mucha desconfianza al aparato gubernamental ya que lo consideran deshonesto e incapaz de erradicar la delincuencia organizada que extorsiona impunemente al sector empresarial de la región.

\section{Retorno inversor}

Las entrevistas a los migrantes retornados inversores se realizaron en seis localidades del Municipio de Salvatierra (Salvatierra, San José del Carmen, Urireo, El Capulín, El Sabino y Maravatío del Encinal). De ellos, el $84.37 \%$ son hombres y el restante $15.63 \%$ son mujeres. La edad promedio de estos inversores retornados es de 38.42 años. En cuanto a escolaridad tenemos que al igual que los propietarios de negocios remeseros sus niveles no son altos. Aunque a diferencia de los anteriores, estos presentan índices de escolaridad un poco más elevados. Así tenemos que el $6.25 \%$ tiene estudios de primaria inconclusa y el $25 \%$ primaria concluida; un $40.62 \%$ tiene el nivel de estudios de secundaria, y el $25 \%$ terminó la educación preparatoria. Lo más que cuenta el migrante retornado es con nivel de carrera técnica (3.12\%), estando ausente los niveles de licenciatura y posgrado.

La mayoría de los retornados inversores (53.12\%) no cuentan con documento legales para ir a Estados Unidos. El resto son legales con residencia permanente $(34.37 \%)$, o son contratados en los programas de trabajo temporal (9.37\%), o cuentan con visa de turista (3.12\%). Llama la atención que ninguno tiene el estatus de ciudadano estadounidense ya que en los últimos años este proceso se ha tomado como opción para muchos migrantes mexicanos por los beneficios que reporta.

Si observamos la edad que tenían los migrantes de retorno cuando se fueron por primera vez a Estados Unidos resalta que $53.12 \%$ estaba en el rango de 15 a 20 años y el $25 \%$ entre los 21 y 30 . Podemos resaltar que tan solo el $3.12 \%$ tenía entre 1 y 14 años, lo que intuimos que cuando se migra de niño disminuye la posibilidad de retornar a su país de origen por efecto de la mermada sociabilización y los pocos referentes culturales vivenciales con la comunidad de origen. Es muy difícil que después de los 40 años cuando se migra por primera vez retornen ya que como nos explicaba algunos migrantes entrevistados que conforme se avanza en edad disminuye la capacidad productiva y el afán de ahorrar y emprender un negocio. Cuando se es joven se trabaja muchas de las veces tiempo extra y es más fuerte el deseo de invertir, escalar en la pirámide social, empoderarse a través del gasto conspicuo y ostentar el rol de exitosos y pletóricos en bienes. De ahí que tan solo se observe que el $15.62 \%$ \% tenía de 31 a 40 años, y el 3.12\% de 41 años en adelante.

La decisión de migrar, las penurias en la adaptación, lo arduo en ahorrar, la negociación con los familiares para planear y optar por el retorno, hacen que se complejice y se emplace el regreso definitivo. El sueño de muchos migrantes por algún día regresar a sus tierras fenece conforme la estancia en el extranjero se prolonga. Las nuevas rutinas, el inédito estilo de vida, los nuevos ámbitos sociales, la reintegración familiar, las asimetrías económicas, la adaptación a la otredad del entorno y la cultura, revierte la intensión inicial de vivir sus últimos años en su localidad. Si retornar es difícil, más complejo es hacerlo para convertirse en empresario.

Visto de cerca tenemos que la duración de la estancia laboral de los migrantes retornados en Estados Unidos en promedio fue de 10.68 años. Desglosado porcentualmente tenemos que el 18.75\% tan solo duró de 1 a 5 años, y donde más cantidad se observa es entre los 6 y 10 años que arrojó el 34.37\% del total de los inversores retornados. Otra cantidad importante fue de los que radicaron de 11 a 15 años con un $21.87 \%$, disminuyendo a $12.5 \%$ de los que 
vivieron en el extranjero de 16 a 20 años. Y el otro $12.5 \%$ se distribuyó entre los 21 y 30 años de estancia en Estados Unidos. Esto significa que más de la mitad de los retornados (53.12\%) trabajan de 1 a 10 años en aquel país y regresan a invertir.

Las causas que adujeron para irse a vivir a Estados Unidos fueron de orden económico y sociocultural, como la falta de oportunidades para laborar, estudiar, ayudar a sus padres, falta de empleo, salarios insuficientes, los hijos les arreglaron documentos legales, los familiares les consiguieron trabajo, seguir al esposo, problemas con familiares del novio, la ilusión de conocer Estados Unidos, por tener una casa y un negocio.

Y se entiende la necesidad económica como una de las causas principales para migrar. El 53.12\% trabajaban en labores agrícolas antes de irse a Estados Unidos, los demás se desempeñaban como choferes, carpintería, bodegas de granos, panaderías, amas de casa, o ayudándoles a sus padres en cuidado del ganado y el campo.

Los migrantes retornados en su mayoría $(68.75 \%)$ solamente radicaron en un solo estado en Estados Unidos. Texas y California cada uno de ellos albergó al $18.75 \%$, seguido de Illinois con el $9.37 \%$ y Florida el $6.25 \%$. Los que tuvieron menos presencia fueron Colorado, Georgia, Arizona, Tennessee y Michigan con un $3.12 \%$ cada uno. Por su parte el $31.25 \%$ de los migrantes radicó en varios estados de aquel país, lo que nos muestra que los migrantes retornados inversores tuvieron poca movilidad geográfica en sus años de estancia en el extranjero.

Las pericias y habilidades laborales aprendidas son diversas y esto se observa ya que el $65.62 \%$ de estos migrantes ejerció en varios trabajos y el restante $34.37 \%$ se desempeñó en uno solo en el periodo de estancia en Estados Unidos. Los que trabajaron solamente en uno lo realizaron principalmente en la agricultura y la jardinería. Y los que laboraron en varios lo hicieron en la agricultura, construcción, fábricas, jardinería y restaurantes.

Las tipologías de la migración de retorno sirven para esclarecer las diferentes causas, consecuencias y clasificaciones de este fenómeno. Así tenemos de manera general quienes retornan por una motivación empresaria, otros por razones familiares, de jubilación, enfermedades, o fortuitamente por deportación, o por muerte. En nuestro caso, de manera muy particular con el segmento del retorno inversor el $84.37 \%$ lo tenía planeado y el $15.62 \%$ tuvo que regresar por circunstancias de deportación, problemas en la familia, divorcio, entre otras.

Dentro de ese espectro de causas y motivaciones que permitieron planear y desear el retorno hay consideraciones que van desde lo económico hasta lo familiar, cultural y psicológico. Los argumentos vertidos por estos empresarios fueron que iban a Estados Unidos por un periodo a ahorrar dinero y poner un negocio en su lugar de origen. Pero llama mucho la atención que gran parte de ellos lo planearon debido al matrimonio con una mujer de su localidad, extrañaban a sus familiares, al pueblo, sus tradiciones y la tranquilidad, a trabajar las tierras de sus padres, y otras más sensibles como la enfermedad y cuidado de algún familiar.

No siempre las visitas frecuentes a su lugar de origen (retorno cíclico o de visita) garantizan un retorno más inmediato o inevitable. En nuestro caso el $34.37 \%$ de los entrevistados tan solo hicieron un viaje de ida y venida en el transcurso de 8 a 22 años que dijeron durar sin venir a su pueblo. Por su parte el $65.62 \%$ tuvieron varias visitas a su lugar de origen, aunque vale resaltar que el $40.62 \%$ afirmaron que la frecuencia de sus visitas estaba entre varias veces al año y los dos años. Notándose con ello que la mayoría de los retornados inversores no realizaron viajes periódicos. La relación transnacional fue de otra naturaleza.

De ahí que también se entienda que el 52.25\% declaró que, si les costó trabajo adaptarse nuevamente a su lugar de origen, el $34.37 \%$ afirmó que la no les costó nada, y el restante $9.37 \%$ solamente un poco. La reinserción fue difícil ya que argumentaron que el trabajo, la comida y la rutina son diferentes, además se gana muy poco y el nivel de vida es diametralmente disímil. Otra explicación de peso es la ausencia de los amigos y familiares que por migrar o muerte han dejado el pueblo. Y los argumentos vertidos por los que no se les fue difícil la adaptación fueron que aquí les gusta más estar y que Estados Unidos solo fue puerto de paso para ahorrar y regresar.

Esta explicación tiene una gran relación cuando se les abordó sobre si les gustó su estancia en Estados Unidos donde el $82.75 \%$ declaró si gustarles, el $10.34 \%$ respondió con un no rotundo y el $6.89 \%$ dijo que más o menos. A los que si les agradó fue debido a las comodidades y porque se tiene más oportunidades en cuanto a trabajo, esparcimiento y ahorro. Mientras que las diferencias culturales, el arraigo a la tierra y la 
vida rutinaria fueron los principales motivos de su no agrado por vivir en suelo estadounidense.

El hábito del ahorro es un elemento que resaltar entre estos migrantes. Los que ahorraron menos fue de 10 a 15 mil dólares, y los más fueron de 50 a 150 mil dólares. La mayoría de los inversores migrantes retornados los medios que utilizaron para ahorrar fue mandarlo a esposa o mamá que lo depositaban en una cuenta bancaria en México, otros optaron por depositarlo en una institución bancaria estadounidense, y los menos ahorrarlo en sus casas.

Pero no todos los migrantes retornados pensaban invertir sus ahorros en una actividad productiva en México al momento de irse a Estados Unidos. El $40.62 \%$ pensó en esta posibilidad antes de irse, el $43.75 \%$ ya estando en Estados Unidos y el restante $15.62 \%$ se decidió cuando retorno y se estableció de nueva cuenta en su lugar de origen. Lo que pensamos si influyó de manera muy importante para decidirse a invertir fue el apoyo y la tradición empresarial en su familia donde el $65.21 \%$ contó con un antecedente. El otro $34.78 \%$ afirmó no haber recibido apoyo ni herencia de iniciativa empresarial.

En los últimos años se ha detonado diferentes formas de inversión productiva migrante. Hay quienes deciden poner un negocio en el país extranjero de residencia, o a través de los negocios remeseros o retornar e invertir. La pregunta obligada es porqué los migrantes retornados no optaron por quedarse en Estados Unidos y poner la empresa en ese país. Las respuestas al respecto son que allá es más difícil, son más estrictos y piden muchos más requisitos y algunos por ser indocumentados. $Y$ por razones culturales de sentirse plenos con sus raíces y tradiciones, y querer regresar para estar con sus familiares, amigos y conocidos. $Y$ estos motivos intangibles fueron los que antepusieron cuando se les cuestionó por qué regresar a un país más pobre y dejar atrás las comodidades de una nación con mayores ingresos y desarrollo económico.

Muy semejante con los negocios remeseros, los migrantes retornados invirtieron su dinero en la compra de tierras para cultivo, tienda de abarrotes, carpinterías, panaderías, en carnicerías, fruterías, restaurante, taquería, taller de hojalatería y pintura, ferretería, entre otros. Y al igual que los negocios remeseros, son de autoempleo o emplean a pocas personas. Los negocios que más cantidad de trabajadores tienen no rebasan los 5 asalariados.
Otro asunto que llama la atención es en relación con el apoyo del gobierno para los migrantes que retornan e invierten. Al cuestionarles al respecto la totalidad de ellos afirmó no haber recibido apoyo alguno. La idea más bien que tienen del gobierno es que es una institución que "en vez de darte te quita", "sola roba", y que únicamente a través de los medios de comunicación se enteran de que el gobierno ayuda, pero desconocen cómo y quiénes lo reciben. Lo que si favoreció para establecer su negocio fue la facilidad en los trámites oficiales para constituirlo legalmente. Para el $79.16 \%$ no fue difícil mientras que al $16.66 \%$ les fue más complicado debido al desconocimiento del procedimiento de registro.

Los migrantes retornados traen diversas habilidades, hábitos y conocimientos que aprendieron en su travesía por Estados Unidos. A pregunta expresa dijeron que aprendieron a vivir sin su mamá, a las labores de la casa como cocinar, lavar, planchar, y a trabajar duro, ser responsable, puntual y valerse a sí mismo. Otros conocimientos importantes fueron aprender el idioma inglés, a manejar herramientas y maquinaria más moderna, las destrezas en la construcción, la pintura, la jardinería, labores agrícolas y ganaderas, a interactuar y manejar personal de trabajo, la mecánica de autos. Otros afirmaron que les enseño a madurar personalmente, a pensar más reflexivamente y conocer cosas propias de un mundo moderno, urbanizado y cosmopolita.

El $60.71 \%$ se sientes un tanto frustrados ya que no hay relación de los trabajos y habilidades aprendidas en Estados Unidos con las labores que desempeñan en su lugar de origen. Aun cuando son propietarios de un negocio la naturaleza de este dista mucho de los trabajos en el extranjero. Por el contrario, el $39.28 \%$ afirmó si haber relación entre ambas experiencias de trabajo, principalmente en el campo, la construcción, pintura y panadería. Pero lo que la mayoría ponderó fue los hábitos de trabajo, esfuerzo, labores en el hogar y el inglés lo que más les ayuda a en su vida cotidiana.

Por último, y contrario a lo que podría pensarse, el $62.06 \%$ de los propietarios retornados si piensan regresar a Estados Unidos ya que consideran que la vida allá es mejor y muchos hijos viven en ese país; otros aducen, que les gustaría ir para ahorra y reinvertir en el negocio, y otros más cuentan que les atrae el hecho de que sus hijos estudien en Estados Unidos. Para el restante $37.93 \%$ las consideraciones del porqué no les gustarían ya regresar al vecino país del norte fueron debido a que el negocio está 
funcionando, por no poseer documentos legales y la familia entera retorno con ellos; $u$ otros argumentos de carácter cultural como sentirse más libre en México y sus tradiciones.

\section{CONCLUSIÓN}

La migración de mexicanos a Estados Unidos ha forjado cambios sustantivos en las últimas décadas que constituyen tanto la acumulación de tendencias previas, como el efecto de procesos estructurales de más corto plazo. Así, la aceleración de los montos de migrantes registrada en estos años forma parte de las tendencias observadas en el conjunto de la migración internacional desde los años ochenta, consecuencia en parte del estímulo a la movilidad espacial propiciado por la globalización. Es decir, aunque se trata de una migración continua, unidireccional, y centenaria entre dos países vecinos, en la actual sobresale por mostrar una intensidad, dimensiones y un dinamismo sin parangón alguno.

Una migración centenaria (que es muy probable que sea el flujo migratorio contemporáneo con más antigüedad en el ámbito mundial) que por cierto ha estado rodeado de complejas y contradictorias circunstancias que son necesarias entenderlas para observar los cambios más significativos que se han presentado en el transcurso del tiempo, y más en especial descubrir los parteaguas, los hitos, y características de la migración contemporánea como una etapa nueva en cuanto a alcance, tecnología, masividad, transnacionalidad, y nuevos patrones migratorios. El problema de las remesas, sus causas y consecuencias en las últimas décadas no escapa a esta complejidad.

Como nos hemos percatado, la problemática de las remesas e inversión migrante plantea retos teóricos y metodológicos de trascendencia. Dependiendo del espacio de experimentación y análisis, global, regional o local, si se localiza en zonas urbanas o rurales, si se toman derroteros y modelos epistemológicos determinados, los resultados arrojarán conclusiones distintas. Aunque lleva años discutiéndose sobre los efectos positivos o negativos, la polémica sigue fresca y basta revisar mucha de la literatura actual al respecto, para darnos cuenta de las diferencias tanto en el abordaje teórico como en las apreciaciones del impacto en las comunidades, las regiones y los países involucrados. Estos son unos de tantos tópicos que se debaten del complejo y muy actual fenómeno migratorio.

Para el estado de Guanajuato, este no es un asunto menor. La migración internacional a Estados Unidos tiene una larga historia en el estado, y, por ende, han sido múltiples los efectos para muchas localidades y municipios, y sin duda alguna, las remesas sociales y económicas han trastocado las fibras más sensibles de la región. Con fines de política pública, la comprensión sistémica, integral y global del fenómeno de la migración y en particular de la inversión migrante, amerita de un análisis más decantado y una comprensión más allá de triunfalismos descontextualizados y cortoplacistas.

Lo que se infiere de esta reflexión es que la inversión remesera y el retorno inversor rebasa las consideraciones volitivas y subjetivas de los potenciales emprendedores. El entrecruce de condiciones macro, meso y microestructurales son esenciales para desahogar proyectos de esta naturaleza. Sin duda, la inversión productiva migrante pasa, en muchos de los casos, por las bien aceitadas redes familiares. Ya sea por altruismo o autointerés se echa a andar la maquinaria de las remesas, los negocios remeseros y el retorno inversor. Pero no se agota ahí. Es necesario tener en cuanta otras variables: macroeconómicas; apoyo institucional de gobierno y privado, certidumbre política y social; recursos naturales e infraestructura; dinámicos mercados locales y regionales; vocación de ahorro, tradición empresarial local y familiar; perspectivas, habilidades, conocimientos y destrezas de los migrantes, entre otros factores.

No es nada deleznable el caudal de recursos que ingresan por concepto de la inversión migrante y los vínculos transnacionales a Guanajuato, por lo que el potencial del espíritu empresarial de los migrantes es considerable, falta encauzarlos y promoverlos con la certeza de que las vocaciones empresariales no se dan a borbotones, cualidades personales y condiciones externas son complemento. 
Por medio de las entrevistas se logró identificar los principales factores que influyen para que los migrantes en Salvatierra, a través de sus familiares, invirtieran en su comunidad. Y para el caso de los retornados, se detallaron las tres fases de su experiencia migratoria, premigración, su estancia en Estados Unidos, aunque esta última fase fue la que más se profundizó. Para la primera fase se obtuvieron datos sobre las variables socio-demográficas y económicas tales como empleo, habilidades, estado civil, sexo, edad de partida, nivel educativo, historial migrante familiar. Para la fase de estancia en el extranjero se obtuvieron datos sobre lugares de residencia, trabajos desempeñados, ingreso, ahorros, remesas, visitas y sus contactos a su comunidad, situación legal y duración. Y para la etapa de retorno e inversión se logró documentar las causas y condiciones a nivel macro, meso y micro que le dieron vida, su vocación empresarial y su relación con las historias laborales de sus padres, la edad de retorno, el capital financiero que trajeron, el tipo de negocios que montaron, las habilidades, hábitos y comportamientos que se pudieron y no aplicar a las condiciones concretas de la comunidad, y sus intenciones de remigrar a Estados Unidos.

El objetivo de este trabajo comparativo fue poner en perspectiva general las causas y consecuencias de los negocios remeseros y el retorno inversor migrante en un municipio guanajuatense con alta intensidad migratoria. Se observó que las determinantes y sus impactos son diversos y de transcendencia para las comunidades de dicho municipio. Esta investigación es preliminar, exploratoria, que nos permitirá abrir nuevas líneas de investigación de estas dos facetas del fenómeno migratorio.

La mayor parte de la literatura sobre el impacto de las remesas, los más, y el retorno, los menos, se han centrado en aspectos económicos, su uso productivo o no productivo y su potencial para reactivar el crecimiento económico. La asignatura pendiente es saber la repercusión de este fenómeno en la estimulación al cambio dentro de una variedad de instituciones económicas y socioculturales como las jerarquías locales de estatus, los espacios y la arquitectura, los patrones y las normas de consumo, la influencia determinante en las expectativas sobre las trayectorias vitales de los niños y jóvenes, los imaginarios colectivos, los simbolismos y motivaciones psico-culturales.

En fin, somos conscientes de lo complejo del fenómeno de la inversión migrante en sus diferentes facetas, sin embargo, esperamos ver cumplido nuestro modesto objetivo de poner en una perspectiva integral, económico y socio cultural, el potencial de las remesas económicas y sociales en el municipio de Salvatierra, Guanajuato, México. En futuras investigaciones iremos desahogando de manera más puntual el impacto de este flujo monetario, social y de valores culturales para la entidad. 


\section{BIBLIOGRAFÍA}

Adams Jr., R. H. y A. Cuecuecha. (2013). The Impact of Remittances on Investment and Poverty in Ghana, World Development, Vol.50, pp.24-40.

Alkhathlan, K. A. (2013). The nexus between remittance outflows and growth: A study of Saudi Arabia, Economic Modelling, Vol.33, pp. 695-700.

Anzoategui, D., A. Demirguc-Kunt y M. S. Martínez Pería. (2014). Remittances and Financial Inclusion: Evidence from El Salvador, World Development, Vol.54, pp.338349.

Appleyard, R. T. (1962). The Return Movement of United Kingdom Migrants from Australia, Population Studies, vol.15, núm.3, Mar. 1962, pp.214-225.

Arowolo, O. O. (2000). Return Migration and the Problem of Reintegration, International Migration, vol. 38, núm.5, pp. 59-82.

Aubry, A., M. Burzynsky, y F. Docquier. (2016). The welfare impact of global migration in OECD countries. Journal of International Economics, vol. 101, pp.1-21.

Black, R. y A. Castoldo. (2009). Return Migration and Entrepreneurship in Ghana and Cote D'Ivore: The Rule of Capital Transfers, Royal Dutch Geographical Society KNAG, vol. 100, núm. 1, pp.44-58.

Cerase, F. P. (1974). Expectations and Reality: A Case Study of Return Migration from the United States to Southern Italy, International Migration Review, vol. 8, núm. 2, pp.245-262.

Chandra, V. P. (1997). Return of the Prodigals-An Analysis of the Impact of the Cycles of Migration and Remigration on Caste Mobility, International Migration Review, vol. 31, núm. 1, pp.162-170.

Clemens, M.A., C. Ozden y H. Rapoport. (2014). Migration and Development Research is Moving Far Beyong Remittances, World Development, Vol. 64, pp.121-124.

Cohen, N. (2013). From nation to profession: Israeli state strategy toward highly-skiller return migration, 19492012, Journal of Historical Geography, Vol. 42, pp.1-11.
CONAPO. (2010). Índices de Intensidad Migratoria México-Estados Unidos. Disponible en http://www. conapo.gob.mx/publicaciones/intensidad_migratoria/ texto/Migracion_Mex_EU.pdf

CONAPO. (2012). Índices de Intensidad Migratoria México-Estados Unidos. Disponible en http://www. conapo.gob.mx/publicaciones/intensidad_migratoria/ texto/Migracion_Mex_EU.pdf

Constant, A., y D. S. Massey. (2002). Return Migration by German Guestworkers: Neoclassical versus New Economic Theories, International Migration, vol. 40, núm. 4, pp.5-38.

Conway, Dennis y Jeffrey H. Cohen, (1998), Consequences of Migration and Remittances for Mexican Transnational Communities, Economic Geography, vol. 74, no.1, pp.26-44.

Dai, T., X. Liu, y B. Xie. (2014). Brain drain reversal and return subsidy, Journal of Comparative Economics, Vol. XXX, pp.XXX-XXX.

Da Vanzo, J. S., y P. A. Morrison. (1981). Return and Other Sequences of Migration in the United States, Demography, vol. 18, núm.1, pp.85-101.

Davis, J., y D. Lopez-Carr. (2014). Migration, remittances and smallholder decision-making: Implications for land use and livelihood change in Central America, Land Use Policy, Vol.36, pp.319-329.

Diatta, M. A. y N. Mbow. (1999). Releasing the Development Potential of Return Migration: The Case of Senegal, International Migration, vol. 37, núm.1 pp.243-266.

Díaz, V., y G. Soydemir. (2013). Regional foreclosures and Mexican remittances: Evidence from the housing market crisis, North American Journal of Economics and Finance, Vol.24, pp.74-86.

Durand, J. (1994). Más allá de la línea, México, CONACULTA.

Durand, J. y D.S. Massey. (2010). New World Orders: Continuities and Changes in Latin American Migration. The Annals of the American Academy of Political and Social Science, vol. 630, pp.20-52. 
Dustmann, C., I. Fadlon, y Y. Weiss. (2011). Return migration, human capital accumulation and the brain drain, Journal of Development Economics, Vol.95, pp.5867.

Facchini, G., T. Frattini, y A.M. Mayda. (2015). International Migration. International Encyclopedia of the Social \& Behavioral Sciences, (Second Edition), pp.511-518.

Fransen, S., y V. Mazzucato. (2014). Remittances and Household Wealth after Conflict: A Case Study on Urban Burundi, World Development, Vol.60, pp.57-68.

Galor, O., y O. Stark. (1990). Migrant's Savings, the Probability of Return Migration and Migrant's Performance, International Economic Review, vol.31, núm. 2, pp.463-467.

Glaser, W. A., y G. C. Habers. (1974). The Migration and Return of Professionals, International Migration Review, vol. 8, núm.2, pp.227-224.

Gmelch, G. (1980). Return Migration, Annual Review of Anthropology, vol.9, pp.135-159.

Gmelch, G.y S. B. Gmelch. (1995). Gender and migration: the readjustment of women migrants in Barbados, Ireland, and Newfoundland, Human Organization, vol. 54, pp.470-473.

Goldring, L. (2004). Family and Collective Remittances to México: A Multi-dimensional Typology, Development and Change, vol. 35, núm. 4, pp. 799-840.

Goldstein, S. (1964). The Extent of Repeated Migration: An Analysis Based on the Danish Population Register, Journal of the American Statistical Association, vol. 59, núm. pp. 1121-1132.

Gowans, G. (2006). Traveling home: British Women Sailing from India, 1940-1947, Women's Studies International Forum, vol. 29, núm. 1, pp.81-95.

Guha, P. (2013). Macroeconomic effects of international remittances: The case of developing economies, Economic Modelling, Vol.33, pp.292-305.

Hatton, T.J. (2014). The economics of international migration: A short history of the debate, Labour Economics, vol.30, pp.43-50.

Herrera, R. (2006). La perspectiva teórica en el estudio de las migraciones, México, Siglo XXI Editores.
Hunt, J. (2004). Are migrants more Skilled than nonmigrants? Repeat, return, and same-employer migrants, Canadian Journal of Economics, vol. 37, núm.4, pp.830849.

Ibarra, M. (2007) (coordinadora). Migración. Reconfiguración transnacional y flujos de población, México: Universidad Iberoamericana Puebla.

INEGI. (2010) Disponible en http://www.inegi.org.mx International Organization for Migration (IOM), (2015). Consultado el 2 de junio de 2016, desde http://www. iom.int/world-migration

Jonkers, K., y L. Cruz-Castro. (2013). Research upon return: The effect of international mobility on scientific ties, production and impact, Research Policy, Vol.42, pp.1366-1377.

Karafolas, S. (1998). Migrant Remittances in Greece and Portugal: Distribution by Country of Provenance and the Role of the Banking Presence, International Migration, vol. 36, núm. 3, pp.357-381.

Karunarathne, W., y J. Gibson. (2014). Financial literacy and remittance behavior of skiller and unskilled immigrant groups in Australia, Journal of Asian Economics, Vol.30, pp.54-62.

Kirwan, F. y F. Harrigan. (1986). Swedish-Finnish Return Migration, Extent, Timing, and Information Flows, Demography, vol. 23, núm.3, pp.313-327.

Klinthall, M. (2006). Retirement Return Migration from Sweden, International Migration, vol. 4, núm, 2, pp. 153180.

Koc, I. y I. Onan. (2005). International Migrants Remittances and Welfare Status of the left-Behind families in Turkey, International Migration Review, vol. 38, núm.1, pp.78-112.

Kosse, A. y R. Vermeulen. (2014). Do General Payment Habits Play a Role?, World Development, Vol.62, pp.213227.

León-Ledesma, M. y M. Piracha. (2004). International Migration and the Role of Remittances in Eastern Europe, International Migration, vol. 42, núm.4, pp.6583.

Lee, A. S. (1974). Return Migration in the United States, International Migration Review, Vol. 8, No. 2, pp.283-300. 
Lozano, Ascencio F. (2007). Migración y desarrollo: remesas y su impacto en la economía mexicana, en: Marcela Ibarra Mateos, (coordinadora), Migración. Reconfiguración transnacional y flujos de población, México, Universidad Iberoamericana Puebla, pp.135144.

Lozano, Ascencio F. y F. Olivera Lozano. (2007). Impacto económico de las remesas en México: un balance necesario, en Marina Ariza y Alejandro Portes, (coordinadores), El país transnacional. Migración mexicana y cambio social a través de la frontera, México, UNAM/Instituto de Investigaciones Sociales, pp. 119150.

McCormick, B., y J. Wahba. (2001). Overseas Work Experience, Savings and Emtrepreneurship Amongst Return Migrants to LDSs, Journal of Development Economics, vol. 48, núm. 2, pp. 164-178.

McLean, Petras E., y M. Kousis. (1988). Returning Migrant Characteristics and Labor Market Demand in Greece, International Migration Review, vol. 22, núm. 4, pp. 586-608.

Marchetta, F. (2012). Return Migration and the Survival of Entrepreneurial Activities in Egypt, World Development, Vol.40, No.10, pp.1999-2013.

Muschkin, C. G., (1993). Consequences of Return Migrant Status for Employment in Puerto Rico, International Migration Review, vol. 27, núm. 1, pp.79102.

Newbold, K. B., y M. Bell. (2001). Return and Onwards Migration in Canada and Australia: Evidence from Fixed Interval Data, International Migration Review, vol. 35, núm. 4, pp.1157-1184.

Ni Laoire, C. (2007). The green grass of home? Return Migration to Rural Ireland, Journal of Rural Studies, vol. 23, núm. 3, pp.332-344.

Papademetriou, D. (1985). Emigration and Return in the Mediterranean Littoral, Comparative Politics, vol. 18, núm. 1, pp.21-39.

Pino, Juste M. R. y C. Verde Diego. (2006). Emigración de retorno: análisis de la situación a través de las historias de vida, Migraciones, núm. 20, pp.200-203.

Poirine, B. (2006). Remittances sent by a growing altruistic diaspora: How do they grow over time?, Asia Pacific Viewpoint, vol. 47, núm. 1, pp.93-108.
Potter, Robert B., D. Conway y G. St. Bernard. (2009). Transnationalism personified: Young Returning Trinidadians In Their Own Words", Royal Dutch Geographical Society KNAG, vol. 100, núm. 1, pp.101113.

Ravinesh Kumar, R. (2013). Remittances and economic growth: A study of Guyana, Economic Sistems, Vol.37, pp.462-472.

Reyes, Tépach M. (2006). El flujo migratorio internacional de México hacia los Estados Unidos y la importancia de las remesas familiares en la economía mexicana, 19902005, Centro de Documentación, Información y Análisis, Cámara de Diputados, pp.1-38.

Salas, Vania B. (2014). International Remittances and Human Capital Formation, World Development, Vol.59, pp.224-237.

Sjaastad, L. A. (1962). The costs and returns to human migration, Journal of Political Economy, vol. 70, pp. 8093.

Tannenbaum, M. (2007). Back and Forth: Immigrants Stories of Migration and Return, International Migration, vol. 45, núm. 5, pp.147-175.

Toren, N. (1976). Return to Zion: Characteristics and Motivations of Returning Emigrants, Social Forces, vol. 54, núm. 3, pp.546-558.

Vanderkamp, J. (1971). Migration Flows, Their Determinants and the Effects of Return Migration, The Journal of Political Economy, vol. 79, núm.5, pp. 10121031.

Vasileva, D. (1992). Bulgarian Turkish Emigration and Return, International Migration Review, vol. 26, núm.2, pp.342-352.

Vera, J., J. Revilla y L. Schatzl. (2013). Determinants and Consequences of Internal Return Migration in Thailand and Vietnam, World Development, Vol. XXX, pp.XXX.

Verde, D. C. (2006). Migración de retorno en Galicia: Aspectos psicosociais e emocionais da segunda xeracion, Revista Gallega de Ciencias Sociais, núm. 5, pp.69-90. 
Vertovec, S. (2006). Transnacionalismo migrante y modos de transformación, en Alejandro Portes y Josh DeWind, (coordinadores), Repensando las migraciones. Nuevas perspectivas teóricas y empíricas, México, Universidad Autónoma de Zacatecas/Miguel Ángel Porrúa, pp.157-190.

Vuorenkosky, L., et-al. (2000). Bilingualism, School Achievement, and Mental Wellbeing: A follow-up of Return Migrant Children, J. Child Psychol. Psychiat, vol. 41, núm. 2, pp.261-266.

Williams, A. M. y V. Baláz. (2005). What Human Capital, Which Migrants? Returned Skilled Migration to Slovakia from the UK, International Migration Review, vol. 39, núm. 2, pp.439-469.

Zarate-Hoyos, G. A. (2004). Consumption and Remittances in Migrant Households: Toward a Productive Use of Remmitances, Contemporany Economic Policy, vol. 22, núm. 2, pp. 555-565.

Zúñiga, E., P.Leite. (2006). Los procesos contemporáneos de la migración México-Estados Unidos: una perspectiva regional, en Elena Zúñiga Herrera, et-al, (coordinadores), Migración México-Estados Unidos. Implicaciones y retos para ambos países, pp. 49-82. México: U de G-CIESAS, Casa Juan Pablos, El Colegio de México. 